\title{
Comparison of temperature shock timing to induced artificial mitotic gynogenesis and androgenesis in common tench
}

\author{
Joanna Nowosad • Dariusz Kucharczyk • Tomasz Liszewski • \\ Katarzyna Targońska • Roman Kujawa
}

Received: 10 January 2014 / Accepted: 9 May 2014/Published online: 23 May 2014

(C) The Author(s) 2014. This article is published with open access at Springerlink.com

\begin{abstract}
The aim of the study was to determine the optimum temperature shock timing to induce androgenetic and gynogenetic growth in common tench (Tinca tinca L.). UV radiation at the dose of $3,456 \mathrm{~J} \mathrm{~m}^{-2}$ was used to inactivate the genome of oocytes (androgenesis) and sperm (gynogenesis). In each case, the optimum timing was sought (between 20 and $60 \mathrm{~min}$ ) before the beginning of diploidization of genetic material with a temperature shock $\left(40^{\circ} \mathrm{C}\right.$, duration $\left.2 \mathrm{~min}\right)$. Eggs were incubated under laboratory conditions at $21{ }^{\circ} \mathrm{C}$. The highest survival rate for androgenotes was observed after the temperature shock was applied for $30 \mathrm{~min}$ and for gynogenotes $40 \mathrm{~min}$ after the activation. The survival rate for embryos did not exceed $2 \%$ in the best variants, either in andro- or gynogenesis. A negative correlation was found to exist between the quality of spawn and the occurrence of spontaneous andro- and gyno-genotes.
\end{abstract}

Keywords Androgenesis · Gynogenesis · Spontaneous diploidization · Tench · UV gametes inactivation

\section{Introduction}

The tench (Tinca tinca L.) is one of the most important species of freshwater fish in many countries of Europe and elsewhere. It is very commonly bred in polyculture with carp,

J. Nowosad · D. Kucharczyk · K. Targońska · R. Kujawa

Department of Lake and River Fisheries, University of Warmia and Mazury in Olsztyn, Olsztyn,

Poland

D. Kucharczyk $(\bowtie)$

Al. Warszawska 117, 10-957 Olsztyn, Poland

e-mail:darekk56@gmail.com; darekk@uwm.edu.pl

T. Liszewski

Department of Ichthyology, University of Warmia and Mazury in Olsztyn, Olsztyn, Poland 
grass carp, European catfish and other thermophilic species (Yilmaz 2002; Kohlmann et al. 2007). Tench is usually bred for commercial purposes and to strengthen the reproductive potential of natural populations (Kohlmann et al. 2007). The increasing market demand for the species has resulted in considerable interest from researchers, mainly in terms of the biology of reproduction, growth rate and survival rate as well as nutrition habits (Garcia et al. 2011; González-Rodríguez et al. 2013). Compared to such species as carp, Cyprinus carpio L., or rainbow trout, Oncorhynchus mykiss, tench grows very slowly (Yilmaz 2002; Wang et al. 2006; Nowosad et al. 2013). Manipulation of its genome offers new breeding and reproduction opportunities for the species.

Androgenesis is a process which involves embryo development without any active participation of a female nuclear genome. The entire genetic material of the offspring is inherited from males. The oocyte genome is inactivated with gamma (May et al. 1988; Babiak et al. 2002) and UV radiation (Pandian and Koteeswaran 1998; Karayücel and Karayücel 2003) and X-rays (Ocalewicz et al. 2010). After being inactivated, eggs are fertilized with sperm of the same species (intra-species androgenesis) (Ocalewicz et al. 2010), or of another one (inter-species androgenesis) (Bercsenyi et al. 1998; Ocalewicz et al. 2013), which produces a haploid zygote (1n). In order to duplicate the father's genome, fertilized eggs are subjected to a temperature (Babiak et al. 2002) or to a pressure shock (Ocalewicz et al. 2010). A genome can also be doubled by dispermia (introducing two chemically bonded sperm to an oocyte) (Nagoya et al. 2010) or using sperm from tetraploid males for fertilization (4n) (Arai et al. 1995).

Gynogenesis produces an organism whose entire genetic material has been inherited from the mother. Gynogenetic development is induced by fertilization of spawn with sperm with a previously inactivated genome, for example, using UV radiation (Kavumpurath and Pandian 1994; Kucharczyk et al. 2014). Subsequently, as is the case in androgenesis, the genetic material of the embryo is duplicated by subjecting a haploid zygote (1n) to a (thermal, pressure or chemical) shock during the first stage of the mitotic development of the embryo. This produces a diploid (2n) zygote (Refstie 1983; Łuczyński et al. 1997). Andro- and gyno-genetic individuals can be used in studies of genetic sex determination and to produce clonal and inbred fish lines. Moreover, clonal and androgenetic fish lines produced by multiple androgenesis are used in such processes as genome sequencing and gene mapping. Together with cryopreservation, androgenesis offers the opportunity to recreate the genetic pool of an endangered species (Rodina et al. 2007; Fopp-Bayat and Ciereszko 2012), biopreservation of breeding lines and the re-introduction of extinct species (Komen and Thorgaard 2007). Despite numerous research studies devoted to androgenesis and gynogenesis, the survival rate of offspring produced in this way is still very low. Optimization of procedures and techniques used in genomic manipulations can be indispensable to regenerate the populations and breeding shoals of many fish species and other vertebrates.

The aim of the study was to determine the optimum temperature shock timing to induce androgenetic and gynogenetic growth in common tench.

\section{Materials and methods}

Breeders and reproduction procedure

In the present study, colored (yellow) males and females of tench and common carp breeders were used from the Polish Anglers Association (PZW) Fish Farm at Halinów, near 
Warsaw (central Poland) and from Oleśnica Fish Farm (west Poland) and 'wild' colored fishes (males and females) from lakes managed by Polish Anglers Association (PZW) Olsztyn (northern Poland). Among the wild tench, there were 15 females and 10 males, with 12 yellow-colored females and 11 tench males. The selected fish (0.5-1.5 kg of body weight) were transported to the hatchery of the Department of Lake and River Fishery where they were placed in 1,000 $\mathrm{dm}^{3}$ tanks equipped for thermo-oxygen control (Kujawa et al. 1999). All the manipulations on spawners were carried out after having the fish anaesthetized in a solution of 2-phenoxyethanol (Sigma-Aldrich, Germany) at a dose of $0.5 \mathrm{~cm}^{3} \mathrm{dm}^{-3}$.

The reproduction of tench was stimulated by double injections of Ovopel (Unic-trade, Hungary) following the procedure described by Kucharczyk et al. (2005), Kujawa et al. (2011) and Targońska et al. (2012). In each experiment, milt was collected from several males. The quality of sperm was expressed as the percentage of motile spermatozoa. Motility was estimated by microscopic $(500 \times)$ observation of sperm activated with $0.5 \%$ $\mathrm{NaCl}$. Samples of sperm with $70-80 \%$ (or more) motile spermatozoa were pooled and used for further treatments and were kept in cold conditions (Kucharczyk et al. 2014). Spawning occurred after $8-18 \mathrm{~h}$ after second injection at a water temperature of $21 \pm 0.5^{\circ} \mathrm{C}$. The oocytes were kept in plastic containers before the experiments $(\mathrm{Ku}-$ charczyk et al. 2014).

Genetic inactivation of spermatozoa and induction of mitotic gynogenesis

Pooled milt (from minimum five dark-colored males in each experiment) was diluted in $0.85 \% \mathrm{NaCl}$ in the ratio 1:9. Two and half $\mathrm{ml}$ of the diluted sperm were spread in a $1 \mathrm{~mm}$ layer on Petri dishes and placed for irradiation on a rocking table with a cycle of $\sim 1 \mathrm{~s}$. The UV lamp $\left(30 \mathrm{~W}, 6.4 \mathrm{~W} \mathrm{~m}^{-2}\right)$ was switched on for at least $30 \mathrm{~min}$ before the onset of irradiation. Before irradiation of sperm, control samples of eggs (150-200 eggs in each sample of one yellow-colored female) were fertilized with small volume $\left(0.05 \mathrm{~cm}^{3}\right)$ of undiluted sperm (control of egg quality: groups C). Experimental groups of eggs were fertilized with $0.5 \mathrm{~cm}^{3}$ of diluted and irradiated sperm (time of irradiation ranged from $9 \mathrm{~min}$, dose of UV irradiation $3,456 \mathrm{~J} \mathrm{~m}^{-2}$ ). During gynogenesis, experimental groups were fertilized with $0.5 \mathrm{~cm}^{3}$ of dark-colored common carp sperm after exposition to a 9 min UV irradiation (an UV irradiation dose of 3,456 $\mathrm{J} \mathrm{m}^{-2}$ ). Inseminated eggs were exposed to thermal shock from 20 to $60 \mathrm{~min}$ after egg activation $\left(40{ }^{\circ} \mathrm{C} ; 2\right.$ min duration). This constituted E20, E25, E30, E35, E40, E50 and E60 groups, respectively. Eggs activated with spermatozoa treated with UV irradiation, but not exposed to the thermal shock, was the additional control group (control of irradiation quality-group I).

Genetic inactivation of DNA oocytes and induction of androgenesis

Eggs of common tench (dark-colored form) during irradiation were kept on Petri dishes in artificial ovarian fluid composed for common carp (Bongers et al. 1994) which was also found to be optimal for tench eggs (Kucharczyk et al. 2014). The dishes with eggs were placed on a rocking table with a cycle of $\sim 1 \mathrm{~s}$. During stirring, the eggs were able to roll in the fluid. An UV lamp $\left(30 \mathrm{~W}, 6.4 \mathrm{~W} \mathrm{~m}^{-2}\right.$ ) was switched on for at least 30 min before the onset of irradiation. During androgenesis, experimental groups were fertilized with $0.05 \mathrm{~cm}^{3}$ of yellow tench form sperm after exposition of the oocytes to a 9 min UV irradiation (an UV irradiation dose of $3,456 \mathrm{~J} \mathrm{~m}^{-2}$ ). Inseminated eggs were exposed to thermal shock from 20 to $60 \mathrm{~min}$ after egg activation $\left(40{ }^{\circ} \mathrm{C} ; 2 \mathrm{~min}\right.$ duration). This 
constituted E20, E25, E30, E35, E40, E50 and E60 groups, respectively. Eggs treated with UV irradiation, but not exposed to the thermal shock, were fertilized using the yellow form of tench sperm (control of irradiation quality_-group I).

Eggs incubation and hatching

The whole procedure during both experiments was carried out in darkness to avoid genetic photo-reactivation (Kaastrup and Horlyck 1987). Before the application of thermal shock, the eggs were kept at $2{ }^{\circ} \mathrm{C}$. After the experiment, the eggs from the individual trial were incubated in small $\left(1 \mathrm{dm}^{3}\right.$ volume each) aquaria, located in a laboratory recirculating system at $21-22{ }^{\circ} \mathrm{C}$, which was found to be the optimum incubation temperature for tench (Kucharczyk et al. 2014). All experimental groups were analyzed in triplicate. Duration of incubation was about 3-3.5 days. Larvae were start for swimming on sixth DPF (days post fertilization). The survival of larvae, their color, normal or abnormal development were checked at seventh DPF. The success of androgenetic development in embryos in present study was determined in few method (Mamcarz et al. 2006; Kucharczyk et al. 2014):

- haploid syndrome (poorly formed retina, stunted body, ect ...),

- color marker (wild-dark color: dominated or yellow: recessive) and,

- morphological marker: the differences between embryos of pure species and their hybrids.

All experimental groups were in triplicates. From induction gyno- and andro-genesis, all experiment was conducted eight times. In all cases, the eggs from one tench females (dark in gynogenesis and yellow in androgenesis) were used.

Statistical analysis

All of the values expressed as percentages were arcsine transformed prior to statistical analysis. The differences in hatching success and in the survival of tench embryos were analyzed using one-way ANOVA and tested by post hoc Duncan's multiple range test $(P<0.05)$.

\section{Results}

The survival rate in groups in which andro- and gynogenesis was induced with UV radiation and temperature shock was much lower than the survival rate in control groups $(P<0.05)$. The mean survival rate in control groups was $70.25 \pm 22.4$ (Table 1$)$. The highest survival rate for androgenotes in the experimental groups was observed after the thermal shock was applied for $30 \mathrm{~min}$ and $40 \mathrm{~min}$ for gynogenotes following activation. The survival rate in those groups was $1.74 \pm 0.23 \%$ for androgenesis and $1.76 \pm 0.32 \%$ for gynogenesis. The difference between the survival rate in groups (irradiation quality control) of androgenotes and gynogenotes did not differ significantly. On the other hand, significant differences in the survival rate $(P<0.05)$ were observed between the other groups (Table 1).

A comparison of the survival rate of embryos in control groups $(\mathrm{C})$ and the occurrence of spontaneous diploidization has shown that the highest percentage of spontaneous diploidization occurred when the lowest survival rate was observed in control groups. This is correlated with the poorer quality of oocytes (Fig. 1). It has also been observed that an 


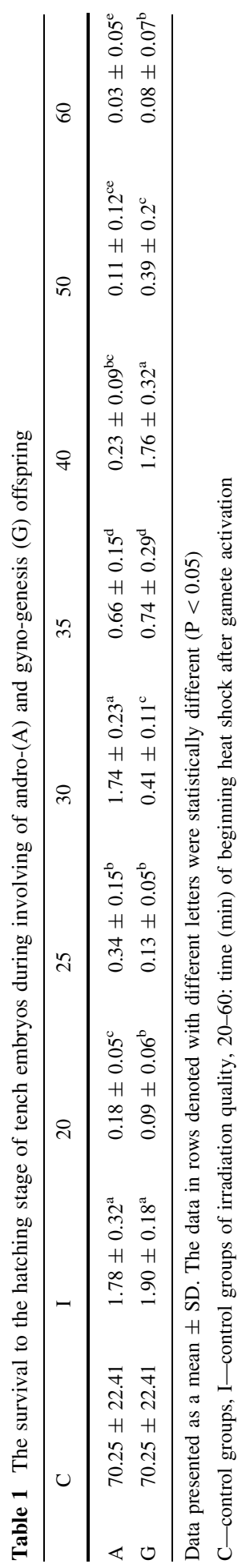


increase in the percentage of malformations in larvae in the control group is correlated with the occurrence of spontaneous diploidization (Fig. 2). The survival of larvae between hatching and start to swimming in diploid specimens was over $95 \%$. Also, the survival in haploid specimens (they did not try to start swimming) was over $90 \%$ at this period.

\section{Discussion}

Techniques of genomic manipulations, including andro- and gynogenesis open great opportunities for developing modern science and aquaculture. However, the techniques of genomic manipulations require further improvement to be fully successful. The greatest difficulties are encountered when brooders caught in the wild are used in experiments; the survival rate of the offspring produced in this manner is usually very low (e.g. Kucharczyk et al. 2008a, 2014). When the process of androgenesis and gynogenesis is induced, the first mitotic division is blocked. To do this, a thermal (hot or cold), chemical or pressure shock is applied. Thermal shocks have been successfully applied in cyprinids (Kwiatkowski et al. 2008). In this experiment, diploidization of the genetic material was induced in andro- and gynogenetic tench with a 2 -min thermal shock at $40{ }^{\circ} \mathrm{C}$. The same type of shock (temperature, duration) was applied when androgenesis was induced in carp, (Bongers et al. 1994; Kwiatkowski et al. 2008) and tench (Kucharczyk et al. 2014).

The survival rate in this study did not exceed $2 \%$ for either androgenotes or gynogenotes (Table 1). The study findings have shown that the survival rate in the andro- and gynogenotes of the tench depends on the time which passes between inactivation and the thermal shock, which stops the first mitotic division in a zygote. This process results in a doubling (2n) of the amount of genetic material. The time in andro- and gynogenesis was 30 and $40 \mathrm{~min}$, respectively. The survival rate in these groups was not significantly different from that in groups I (irradiation quality), for either androgenesis $(1.78 \pm 0.32 \%)$ or for gynogenesis $(1.90 \pm 0.18 \%)$. Kucharczyk et al. (2014) induced inter-species androgenesis in tench using oocytes of bream (Abramis brama) and carp and found, similar to this study, the optimum timing for the thermal shock $\left(40{ }^{\circ} \mathrm{C}\right.$, with an incubation temperature of $21^{\circ} \mathrm{C}$ ), to be $30 \mathrm{~min}$ after inactivation. Decreasing the incubation temperature by $1{ }^{\circ} \mathrm{C}$ results in extending the time after which the thermal shock should be applied. Kucharczyk et al. (2014) found a shock applied $40 \mathrm{~min}$ after fertilization, with an incubation temperature of $20^{\circ} \mathrm{C}$, to be the most effective in inducing androgenesis in tench. Despite inter-species androgenesis being applied in the study (Kucharczyk et al. 2014), the survival rate of the androgenetic tench did not exceed $2 \%$. Intra-species androgenesis conducted in this experiment also did not result in an increased survival rate of the offspring. A similar relationship between the time before the thermal shock $\left(42{ }^{\circ} \mathrm{C}\right.$, duration $4 \mathrm{~min}$ ) was applied after fertilization was observed by Myers et al. (1995) who conducted mitotic andro- and gynogenesis in Nile tilapia (Oreochromis niloticus). The authors found that the highest survival rate of andro- and gynogenetic offspring of Nile tilapia could be achieved when a thermal shock was applied $25 \mathrm{~min}$ (androgenesis) and 27.5 min (gynogenesis) after spermiation and with eggs incubated at $28{ }^{\circ} \mathrm{C}$. A similar relationship was observed in this study for tench; this means that a thermal shock applied to stop the first mitotic division in inducing androgenetic development should be applied earlier than when gynogenetic development is induced. Meanwhile, Myers et al. (1995) noted that the shock applied in order to duplicate genetic material in a diploid zygote should be earlier than in a haploid (andro- or gyno-genetic) zygote. The cause of the differences in the timing of the first division in a diploid zygote (androgenetic and 


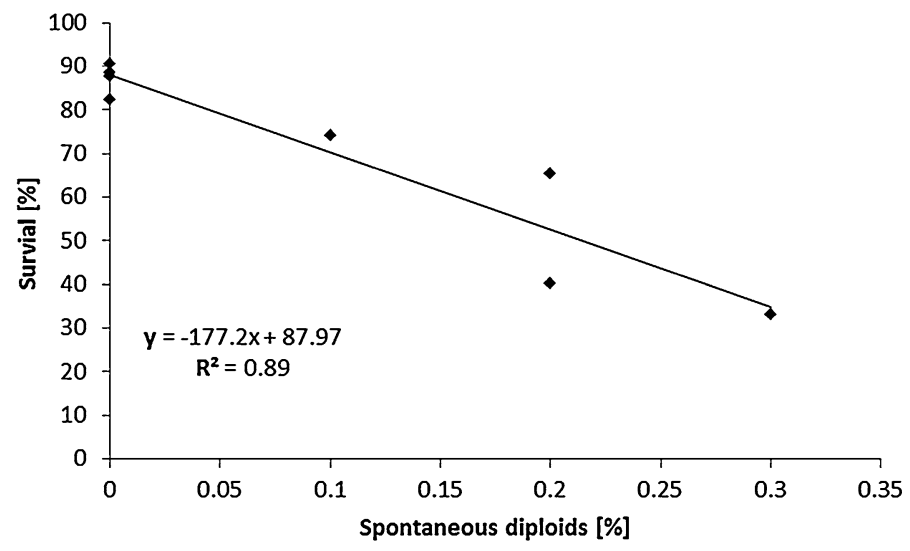

Fig. 1 Relationship between embryo survival in control group (C) and the percentage of spontaneous diploids in the experimental group

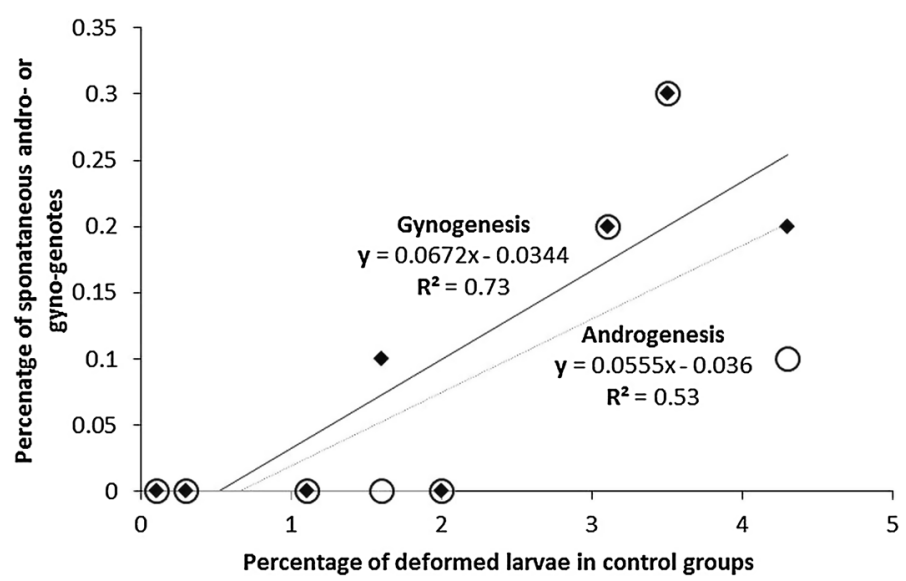

Fig. 2 Relationship between percentage of larvae malformations in the control group and the percentage of spontaneous andro- (open circle) and gynogenesis (black square)

gynogenetic) has not been identified. It may be attributed to a delay in mitosis in haploid (1n) organisms compared to diploid (2n) organisms (Myers et al. 1995). The cause of the earlier division in an androgenetic zygote than in a gynogenetic zygote remains unknown.

This experiment revealed spontaneous diploidization which depended on the embryo survival rate in the control group. When the embryo survival rate in the control group was lower, a higher percentage of duplicated cells (embryos) appeared spontaneously in groups I, whereas a higher percentage of spontaneous diploids was observed in the groups with a higher percentage of malformations. Aegerter and Jalabert (2004) investigated the quality of oocytes in rainbow trout and showed that the older the post-ovulatory oocytes was, the more significantly the egg survival rate dropped and the embryo malformation rate increased. Moreover, the authors found that post-ovulatory oocyte aging results in a higher percentage of spontaneous triploids in offspring. It may be concluded that those effects (Aegerter and Jalabert 2004), as well as those observed in this experiment, depend on the 
oocyte quality. In general, low gametes quality results in a higher probability of spontaneous di- and triploidization and deformations in the offspring. A spontaneous increase in genetic material has been observed in other cyprinid species, such as: ide (Leuciscus idus) (Kucharczyk et al. 2008b), bighead carp (Aristichthys nobilis) (Ye et al. 2008) and in Nile tilapia of the cichlid family (Ezaz et al. 2004) and American paddlefish (Polyodon spathula) of the paddlefish family (Zou et al. 2011).

It may be concluded from this experiment that the timing of a shock applied in order to stop the first mitotic division in andro- and gynogenetic offspring differs. This means that the protocol developed for induction of gynogenesis cannot be directly transposed to androgenesis and vice versa. Both processes require separate protocols. Moreover, spontaneous diploidization is also possible, which correlates with gamete quality. Lower oocyte quality was directly correlated with a higher percentage of spontaneous diploids and malformations in the offspring.

Open Access This article is distributed under the terms of the Creative Commons Attribution License which permits any use, distribution, and reproduction in any medium, provided the original author(s) and the source are credited.

\section{References}

Aegerter S, Jalabert B (2004) Effects of post-ovulatory oocyte ageing and temperature on egg quality and on the occurrence of triploid fry in rainbow trout, Oncorhynchus mykiss. Aquaculture 231:59-71

Arai K, Ikeno M, Suzuki R (1995) Production of androgenetic diploid loach Misgurnusan guillicaudatus using spermatozoa of natural tetraploids. Aquaculture 137:131-138

Babiak I, Dobosz S, Goryczko K, Kuźmiński H, Brzuzan P, Ciesielski S (2002) Androgenesis in rainbow trout using cryopreserved spermatozoa: the effect of processing and biological factors. Theriogenology 57:1229-1249

Bercsenyi M, Magyary I, Urbanyi B, Orban L, Horvath L (1998) Hatching out goldfish from common carp eggs: interspecies androgenesis between two cyprinid species. Genome 41:573-579

Bongers ABJ, Veld EPC, Abo-Hasema K, Bremmer IM, Eding EH, Komen J, Richter CJJ (1994) Androgenesis in common carp (Cyprinus carpio L.) using UV irradiation in a synthetic ovarian fluid and heat shock. Aquaculture 122:119-132

Ezaz MT, McAndrew BJ, Penman DJ (2004) Spontaneous diploidization of the maternal chromosome set in Nile tilapia (Oreochromis niloticus L.) eggs. Aquacult Res 35:271-277

Fopp-Bayat D, Ciereszko A (2012) Microsatellite genotyping of cryopreserved spermatozoa for the improvement of whitefish semen cryobanking. Cryobiology 65:196-201

Garcia V, Celada JD, Carral JM, González R, González A, Sáez-Royuela M (2011) A comparative study of different preparations of decapsulated Artemia cysts as food for tench (Tinca tinca L.) larvae. Ani Feed Sci Tech 170:72-77

González-Rodríguez A, Celada JD, Carral J M, Sáez-Royuela M, Fuertes JB (2013) Evaluation of a practical diet for juvenile tench (Tinca tinca L.) and substitution possibilities of fish meal by feather meal. Ani Feed Sci Tech. doi:10.1016/j.anifeedsci.2013.10.001

Kaastrup P, Horlyck V (1987) Development of single method to optimize the conditions for producing gynogenetic offspring, using albino rainbow trout, Salmo gairdneri Richardson, females as an indicator for gynogenesis. J Fish Biol 31:29-33

Karayücel I, Karayücel S (2003) Optimisation of UV treatment duration to induce haploid androgenesis in the Nile tilapia (Oreochromis niloticus L.). Tur J Vet Anim Sci 27:401-407

Kavumpurath S, Pandian TJ (1994) Induction of heterozygous and homozygous diploid gynogenesis in Bettasplendens (Regan) using hydrostatic pressure. Aquacult Res 25:133-142

Kohlmann K, Kersten P, Flajšhans M (2007) Comparison of microsatellite variability in wild and cultured tench (Tinca tinca). Aquaculture 272:147-151

Komen H, Thorgaard GH (2007) Androgenesis, gynogenesis and the production of clones in fishes: a review. Aquaculture 269:150-173 
Kucharczyk D, Kujawa R, Mamcarz A, Targońska-Dietrich K, Wyszomirska E, Glogowski J, Babiak I, Szabo T (2005) Induced spawning in bream (Abramis brama L.) using pellets containing GnRH. Czech J Anim Sci 50:89-95

Kucharczyk D, Targońska K, Łuczyński MJ, Szczerbowski A, Kwiatkowski M, Kujawa R (2008a) Androgenesis of ide, Leuciscus idus (L.), using chub, Leuciscus cephalus (L.), eggs. Arch Pol Fish 16:453-457

Kucharczyk D, Łuczyński MJ, Woźnicki P, Kujawa R, Szczerbowski A, Targońska K, Mamcarz A (2008b) Spontaneous gynogenesis in ide, Leuciscus idus (L.). Arch Pol Fish 16:447-451

Kucharczyk D, Żarski D, Targońska K, Łuczyński M J, Szczerbowski A, Nowosad J, Kujawa R, Mamcarz A (2014) Induced artificial androgenesis in common tench, Tinca tinca (L.), using common carp and common bream eggs. Ital J Anim Sci 13:196-200

Kujawa R, Kucharczyk D, Mamcarz A (1999) A model system for keeping spawners of wild and domestic fish before artificial spawning. Aquac Eng 20:85-89

Kujawa R, Kucharczyk D, Mamcarz A, Żarski D, Targońska K (2011) Artificial spawning of common tench Tinca tinca (Linnaeus, 1758), obtained from wild and domestic stocks. Aquac Int 19:513-521

Kwiatkowski M, Kucharczyk D, Szczerbowski A, Łuczyński M J, Mamcarz A, Jamróz M (2008) Optimizing conditions for androgenesis induction in koi carp. Elect J Pol Agric Univ 11(1). http://www. ejpau.media.pl/volume11/issue2/art-09.html

Łuczyński MJ, Glogowski J, Kucharczyk D, Łuczyński M, Demska-Zakęś K (1997) Gynogenesis in northern pike (Exox lucius L.) induced by heat shosk-preliminary data. Pol Arch Hydrobiol 44:25-32

Mamcarz A, Kucharczyk D, Kujawa R (2006) Reciprocal hybrids of tench Tinca tinca (L.) $\times$ bream Abramis brama (L.), and tench $\times$ carp Cyprinus carpio L., and some characteristics of their early development. Aquacult Int 14:27-33

May B, Henley KJ, Krueger CC, Gless SP (1988) Androgenesis as a mechanismfor chromosome set manipulation in brook trout (Salvelinus fontinalis). Aquaculture 75:57-70

Myers JM, Penman DJ, Basavaraju Y, Powell SF, Baoprasertkul R, Rana KJ, Bromage N, McAndrew BJ (1995) Induction of diploid androgenetic and mitotic gynogenetic Nile tilapia (Oreochromis niloticus L.). Theor Appl Genet 90:205-210

Nagoya H, Kawamura K, Ohta H (2010) Production of androgeneticamago salmon Oncorhynchus masouishikawae with dispermy fertilization. Fish Sci 76:305-313

Nowosad J, Żarski D, Biłas M, Dryl K, Krejszeff S, Kucharczyk D (2013) Dynamics of ammonia excretion in juvenile common tench, Tinca tinca (L.), during intensive rearing under controlled conditions. Aquac Int 21:629-637

Ocalewicz K, Dobosz S, Kuźmiński H, Nowosad J, Goryczko K (2010) Chromosome rearrangements and survival of androgenetic rainbow trout (Oncorhynchus mykiss). J Appl Genet 51:309-317

Ocalewicz K, Kuźmiński H, Pomianowski K, Dobosz S (2013) Induction of androgenetic development of the brook charr (Salvelinus fontinalis) $\times$ Arctic charr (Salvelinus alpinus) hybrids in eggs derived from the parental species. Reprod Biol 13:105-112

Pandian TJ, Koteeswaran R (1998) Ploidy induction and sex control in fish. Hydrobiologia 384:167-243

Refstie T (1983) Induction of diploid gynogenesis in Atlantic salmon and rainbow trout using irradiated sperm and heat shock. Can J Zool 61:2411-2416

Rodina M, Gela D, Kocour M, Hadi Alavi SM, Hulak M, Linhart O (2007) Cryopreservation of tench, Tinca tinca, sperm: sperm motility and hatching success of embryos. Theriogenology 67:931-940

Targońska K, Perkowski T, Żarski D, Krejszeff S, Mamcarz A, Kujawa R, Kucharczyk D (2012) Method of evaluation of wild common tench, Tinca tinca (L.), female suitability for artificial reproduction during the spawning season. Ital J Anim Sci 11:164-168

Wang J, Liu H, Min W, Tong J, Guan M, Yuzhang Han Y, Gong L, Huang Z, Ren J, Zhang J, Zheng H (2006) Induced meiotic gynogenesis in tench, Tinca tinca (L.) using irradiated heterogenic sperm. Aquacult Int 14:35-42

Ye Y, Wang Z, Wu Q (2008) Increasing the genetic uniformity of bighead carp [Aristichthys nobilis (Richardson)] by means of spontaneous diploidization of gynogenetically activated eggs. Aquacult Res 39:205-211

Yilmaz F (2002) Reproductive biology of the tench Tinca tinca (L., 1758) inhabiting Porsuk Dam Lake (Kutahya, Turkey). Fisher Res 55:313-317

Zou YC, Wei QW, Zeng LB, Li P (2011) Production of gynogenetic diploid Polyodon spathula using fertilization with irradiated sperm followed by spontaneous diploidization and distant hybridization caused by heat shock. J Appl Ichthyol 27:505-509 